\title{
Effects of depot neuroleptics on driving performance in chronic schizophrenic patients
}

\author{
Kevan R Wylie, David J Thompson, Hiram J Wildgust
}

\begin{abstract}
Patients who are prescribed psychotropic medication may be expected to have some impairment in general attention and concentration and in measures of psychological and motor performance. These impairments may be due to the illness itself, the medication or the combination of both. Twenty two patients who were receiving depot neuroleptics for chronic schizophrenia were compared with sixteen control subjects in their performance on simulated driving tests. There was a significant decrement in driving performance in the index group compared with a normal control group.
\end{abstract}

$(\Im$ Neurol Neurosurg Psychiatry 1993;56:910-913)

The current policy of the Department of Health is that drivers suffering from any disease or disability, or taking any medication for more than a temporary duration-if it is likely to cause them to be a danger to the public-must declare this to the Driver and Vehicle Licensing Centre. Any mental disorder requiring treatment as an inpatient may lead to disqualification from driving.

Studies of drug consumption by patients involved in traffic accidents show that between 11-20\% are taking psychotropic drugs, but the extent to which the drug(s) have contributed to the causation of accidents is unknown. ${ }^{1}$

An epidemiological pilot study showed that before treatment mentally ill subjects have higher accident rates than those of matched controls, but after treatment they appear to be safe drivers. ${ }^{2}$ A person receiving effective treatment for an illness might actually derive beneficial effect in terms of road safety. ${ }^{34}$ Parkinsonism, however, is likely to be the main mechanism by which neuroleptic drugs may impair driving. Madeley et al, ${ }^{5}$ showed that naturally occurring Parkinson's disease does impair performance on simulated driving tests compared with normal controls.

The drugs used to treat schizophrenia, usually neuroleptics, are all potentially sedative and may lead to drowsiness, and may potentially increase the risk of a road traffic accident. Despite this, and the severe disturbance in psychological functioning, two surveys of patients admitted to hospital for schizophrenia were not found to have an increased road traffic accident rate. ${ }^{67}$ Silverstone ${ }^{8}$ reviewed the influence of psychiatric disease and its treatment on driving per- formance. He concluded that schizophrenia does not appear to pose any particular threat for increasing the risk of a road traffic accident (RTA), including those patients on regular oral antipsychotic medication.

Previous studies have shown that patients suffering from schizophrenia have prolonged reaction times to psychological testing. ${ }^{910}$ Most studies have involved patients receiving an oral neurolopetic drug which may further impair reaction time through several mechanisms. The improvement of the acute psychosis may increase vigilance and even improve driving performance. ${ }^{11} 12$

The effect of depot neuroleptics driving performance in chronic schizophrenic patients who are currently well is not clear. No study has attempted to separate out the various factors which could each affect the reaction time. This study focuses on the stable nonpsychotic schizophrenic patients who are arguably more likely to drive than those suffering from an acute state of the illness.

\section{Materials and methods}

Three groups of subjects: chronic schizophrenic patients receiving flupenthixol decanoate; chronic schizophrenic patients receiving fluphenazine decanoate; and normal subjects, were compared on tests of simulated driving.

The index groups consisted of patients aged 18-65 years of age. A diagnosis of schizophrenia was confirmed using the criteria stated in the Diagnostic and Statistical manual of mental disorders. ${ }^{13}$ They had all received a depot neuroleptic for at least three months. All patients giving consent were included. Seven patients and seven control subjects currently drove a motor vehicle. One patient had previous driving experience.

Patients were excluded if they were receiving any other regular medication with the exception of procyclidine.

The control subjects were novices to the computer tasks, and were matched for age and driving status. None were currently taking any regularly prescribed or bought overthe-counter medication.

Control subjects were assessed in the same way on the simulated driving tests as the index subjects. Patients were asked to attend any one morning between one and ten days after their last depot injection. All subjects were asked to refrain from taking any medication, including procyclidine, for forty eight hours before the morning of the test. No other limitations were insisted upon. 
The index sample had the following initial assessments: 1) The current psychiatric state of the patient was assessed using the Brief Psychiatric Rating Scale (BPRS); ${ }^{14}$ 2) Assessment of Parkinsonism was made using the Simpson-Angus scale, ${ }^{15}$ and the measurement of tardive dyskinesia by using the Simpson-Lee scale; ${ }^{16}$ 3) The stablised drug dose was recorded for each patient.

The psychomotor tasks were assessed using a BBC/Acorn computer for both the index sample and the control group and are described below.

In the simulated driving task, subjects were presented with a stylised image of a road along which they were required to "drive" using a full-sized steering wheel. A secondary task was to respond to critical stimuli (the changing of one of either set of traffic lights on the display screen from a green light to a red light) by moving the right foot from an accelerator pedal to a brake pedal as fast as possible. The measures recorded were steering accuracy as measured using a tracking task, brake reaction time and number of nonresponses to a red light. The rationale for the use of this simulator is described by Hindmarch. ${ }^{17}$

Each subject had a standard practice period where assistance was given by the investigator if necessary - there were five practice sessions (trial A) then three further sessions (trial B).

\section{Results}

The demographic features of the groups are shown in table 1 . Fifteen patients were receiving flupenthixol decanoate and seven fluphenazine decanoate. Comparisons between the two groups on the driving simulator are shown in table 2.

Table 1 Characteristics of control and index groups

\begin{tabular}{lll}
\hline & Controls & Patients \\
\hline Age range (years): & $24-65$ & $21-62$ \\
Mean age (years): & $44 \cdot 1$ & $45 \cdot 7$ \\
Male/female: & $6 / 10$ & $13 / 9$ \\
Drivers/Non-drivers: & $7 / 9$ & $8 / 14$ \\
\hline
\end{tabular}

Table 2 Comparisons between control and patients groups on the driving simulator

\begin{tabular}{|c|c|c|c|}
\hline & Controls $(n=16)$ & Patients $(n=22)$ & $P$ \\
\hline \multicolumn{4}{|c|}{$\begin{array}{l}\text { Median RT: } \\
\text { seconds (range) }\end{array}$} \\
\hline $\begin{array}{l}\text { Trial A } \\
\text { Trial B }\end{array}$ & $\begin{array}{l}0.82(0.51-1.31) \\
0.62(0.46-0.88)\end{array}$ & $\begin{array}{l}1.08(0.63-1.95) \\
0.76(0.3-2.03)\end{array}$ & $\begin{array}{l}0.006 \\
0.036\end{array}$ \\
\hline \multicolumn{4}{|c|}{$\begin{array}{l}\text { Median accuracy: } \\
\text { (range) }\end{array}$} \\
\hline $\begin{array}{l}\text { Trial A } \\
\text { Trial B }\end{array}$ & $\begin{array}{l}51 \cdot 5(21-86) \\
38(18-56)\end{array}$ & $\begin{array}{l}99 \cdot 5(48-436) \\
70(29-186)\end{array}$ & $\begin{array}{l}0.005 \\
0.002\end{array}$ \\
\hline \multicolumn{4}{|c|}{ Median lights missed: } \\
\hline $\begin{array}{l}\text { Trial A } \\
\text { Trial B }\end{array}$ & $\begin{array}{l}6 \cdot 5(0-21) \\
0\end{array}$ & $\begin{array}{r}10(1-48) \\
0(0-32)\end{array}$ & $\begin{array}{l}0.026 \\
0.03\end{array}$ \\
\hline
\end{tabular}

KEY: (Median Reaction Time to press brake pedal; Median Accuracy for tracking task, and Median lights missed for Accuracy for tracking task, and Median lights missed for
number of red lights for which brake pedal was not pressed).
Table 3 Comparisons between control and patient subjects for those who drove a motor vehicl

Controls $(n=7) \quad$ Patients $(n=8) \quad P$

Median RT:

seconds (range)

$\begin{array}{llll}\text { Trial A } & 0.72(0.51-0.84) & 0.97(0.72-1 \cdot 19) & 0.004\end{array}$

$\begin{array}{llll}\text { Trial B } & 0.60(0.49-0.73) & 0.67(0.59-0.83) & 0.03\end{array}$

Median accuracy:

(range)

$\begin{array}{llll}\text { (range) } & 44(21-51) & 62(48-146) & 0.006\end{array}$

Trial B $\quad 31(18-48) \quad 63(29-152) \quad 0.05$

Median lights missed:

$\begin{array}{llll}\mathbf{n} \text { (range) } & & & \\ \text { Trial A } & 0(0-11) & 7.5(1-24) & 0.11\end{array}$

\begin{tabular}{cccc} 
Trial B & $0(0-11)$ & $7.5(1-24)$ & 0.11 \\
\hline
\end{tabular}

KEY: (Median Reaction Time to press brake pedal; Median Accuracy for tracking task, and Median lights missed for number of red lights for which brake pedal was not pressed).

Table 4 Comparisons between control and patient subjects for those who did not drive a motor vehicle

\begin{tabular}{|c|c|c|c|}
\hline & Controls $(n=9)$ & Patients $(n=14)$ & $P$ \\
\hline \multicolumn{4}{|c|}{$\begin{array}{l}\text { Median RT: } \\
\text { seconds (range) }\end{array}$} \\
\hline $\begin{array}{l}\text { Trial A } \\
\text { Trial B }\end{array}$ & $\begin{array}{l}0.97(0.54-1.31) \\
0.78(0.46-0.88)\end{array}$ & $\begin{array}{l}1.17(0.63-1.95) \\
0.86(0.3-2)\end{array}$ & $\begin{array}{l}0.085 \\
0.097\end{array}$ \\
\hline \multicolumn{4}{|c|}{ Median accuracy: } \\
\hline $\begin{array}{l}\text { Trial A } \\
\text { Trial B }\end{array}$ & $\begin{array}{l}71(42-86) \\
51(26-56)\end{array}$ & $\begin{array}{r}106(64-436) \\
77(46-186)\end{array}$ & $\begin{array}{l}0.002 \\
0.002\end{array}$ \\
\hline \multicolumn{4}{|c|}{ Median lights missed: } \\
\hline Trial A & $8(3-21)$ & $13(3-48)$ & $0 \cdot 11$ \\
\hline Trial B & 0 & $1.5(0-32)$ & 0.69 \\
\hline
\end{tabular}

KEY: (Median Reaction Time to press brake pedal; Median Accuracy for tracking task, and Median lights missed for number of red lights for which brake pedal was not pressed).

There were significant differences between the control and treated group for driving accuracy (trial A: Mann-Whitney $Z=$ $-3.71, p=0.005$; trial $B: Z=-3.96, p=$ 0.002 ), reaction time (trial $A: Z=-2 \cdot 73$, $\mathrm{p}=0.006$; trial $\mathrm{B}: \mathrm{Z}=-2 \cdot 09, \mathrm{p}=-0.036)$ and non-response to a red light (trial $A$ : $Z=-2 \cdot 2, p=0.026 ;$ trial $B: Z=-2 \cdot 13$, $\mathrm{p}=0.03)$. There were no significant differences between the two treated groups.

Tables 3 and 4 examine the importance of driving status and compares drivers with nondrivers both in the control and the index groups.

Five other factors were considered to have some effect on performance in the tests. These were age, drug dosage, BPRS score, Parkinsonism and tardive dyskinesia. In the control group there was a significant positive correlation between age and driving accuracy in both trial A (Spearman's $r=0.57, p=$ $0.026)$ and trial $B(r=0.58, p=0.022)$. This was not seen in the patient group. There was no correlation between drug dose, BPRS score or tardive dyskinesia and driving performance in the patient group. There was a significant positive correlation between Parkinsonism and reaction time trial $A$ $(\mathrm{r}=0.43, \mathrm{p}=0.05)$.

\section{Discussion}

Depot neuroleptics are one of the mainstay treatments in chronic schizophrenia. The effects they may have on driving performance has been largely ignored. This study has compared chronic schizophrenic patients receiv- 
ing two different depot neuroleptic drugs with a non-medicated normal population. The schizophrenic patients showed impairment in driving performance, judged by driving accuracy, reaction time to braking at a red light and non-response to a red light. The impairments in driving performance showed significant differences between the control and treated groups and were consistent over two trials.

There was also a consistent detriment of performance when separating drivers and non-drivers. The effect was most noticeable for driving accuracy but also evident in the reaction time to braking at a red light.

These findings would support previous findings that psychomotor performance is impaired in chronic schizophrenic subjects and that medication might influence the degree of impairment. The confounding variables of schizophrenia and medication cannot be easily separated. We found no schizophrenic patients in Leeds on no medication other than by default. This group would not be identified until clinically unwell and then would have a high BPRS score. They would then be different from the stable population studied and unlikely to cooperate in the study. The alternative, a group of control patients on depot medication for three months would be equally difficult to establish.

The index group were well stabilised on their medication. Those patients on an anticholinergic medication such as procyclidine, stopped this oral medication for a period of forty eight hours before the test. Procyclidine has a short half-life of twelve hours, ${ }^{18}$ this ensured that it was virtually eliminated from the body by the time of testing. Compliance with depot medication was checked on each occasion by contacting the appropriate community nurse or general practitioner.

The index sample has a potential source of bias in that only those patients who felt confident in their general capabilities, which may include driving were volunteering to attend the hospital study. Of all suitable patients for entry into the study, only three refused to attend for reasons of recent worsening of mental state, physical disability and reason not stated.

It remains unclear to what extent performance on a driving simulator reflects real driving ability. ${ }^{19}$ Nevertheless, a recent Consensus Development Panel ${ }^{20}$ concluded that tests using driving simulators may be a better measure of reflecting driving skills than tests of cognitive and motor functions.

From a practical point of view, and disregarding any other difficulties there are in the external validity of the test procedure, then the differences in the medians of the simulated driving tests between groups can be said to be representative of impaired driving accuracy and a slowed reaction time when actually driving. Interpretation of the impairment in driving accuracy is difficult in absolute terms. The Highway $\mathrm{Code}^{21}$ quotes the shortest stopping distances based on the average family saloon. In town driving of 30 miles per hour, the normal thinking distance is 30 feet $(9.1$ metres). The difference in the median of 0.07 seconds between the two groups of drivers leads to an increase in the thinking distance of 3.5 feet. This is an increase of just over $10 \%$.

For those who do drive, Nicholson ${ }^{22}$ has noted that there are other skills involved in driving other than those tested for using a simulator. These include the personality of the driver and the more subtle effect of drugs on decision making and the behavioural integrity of the patient. Hindmarch ${ }^{23}$ has emphasised the need to consider these and other variables rather than accept the results from a unitary test of car handling ability. Factors such as decision taking, risk assessment, memory and short term handling of information could be further avenues of research in a similar sample to that studied above.

It is not clear how much of the impairment is due to the chronic defect state of schizophrenia and how much is due to the medication, or a side-effect of the medication. Movement disorder showed some positive correlation with adverse performance. There appears to be a hierarchy where control drivers perform best in terms of driving accuracy and reaction time and treated schizophrenic patients perform worst. Interestingly, control non-drivers show greater accuracy but slower reaction times than treated patient drivers.

The implications from a small study such as this on advising patients on driving is unclear. The detrimental effect on driving accuracy and the lengthening of the thinking distance by over ten per cent is however an important consideration to be borne in mind until further studies in this previously unconsidered group of patients can be repeated, and the significance of the steering track test further evaluated. This is important as more chronic patients who are non-drivers become rehabilitated into the community. Regular review of psychopathology and movement disorders by the physician is necessary, especially in those seeking advice on their suitability to drive a motor vehicle.

We thank Professor R H S Mindham for his advice throughout the study; Dr P McKenna for training in use of the movement disorder scales and $\operatorname{Dr} S$ Morley for statistical advice.

1 Beeley L. Drugs and medicines. Medical aspects of fitness to drive: Medical commission on accident prevention. 4th ed. London: HMSO 1985:65-9.

2 Eelkena RC, Brosseau J, Koshnick R, McGee C. A statistical study on the relationship between mental illness and traffic accidents-a pilot study. Am $\mathcal{F}$ Public Health. 1970;60:459-69.

3 Havard JDJ. Medical aspects of fitness to drive: Medical Commission on Accident Prevention, 3rd ed. London: HMSO 1976:43-52.

4 Seppala T, Linnoila M, Mattila MJ. Drugs, alcohol and driving. Drugs 1979;17:389-408.

5 Madeley $P$, Hulley JL, Wildgust H, Mindham RHS Parkinson's disease and driving ability. $f$ Neurol Parkinson's disease and driving

6 Crancer A, Quiring DL. The mentally ill as motor vehicle operators. Am F Psychiatry 1969;126:807-13.

7 Kastrup M, Dupont A, Bille M, Lund H. Traffic accidents involving psychiatric patients. Acta Psychiatr Scand 1978;58:30-9.

8 Silverstone T. The influence of psychiatric disease and 
its treatment on driving performance. Int Clin Psychopharmacol 1988;3(Suppl 1):59-66.

9 Shakow D. Psychological deficit in schizophrenia. Behav Sci 1963;8:275-305.

10 Savage PPE, Wilkinson V. Reaction time in psychiatric patients: pilot study. $N Z$ Med F 1971;73:285-8.

11 Bech P. Mental illness and simulated driving: Before and during treatment. Pharmacopsychiatry 1975;8:143-50.

12 Shagass C, Roemer RA, Amadeo M. Eye-tracking performance and engagement of attention. Arch Gen Psychiatry 1976;33:121-5.

13 American Psychiatric Association. Diagnostic and Statistical manual of mental disorders, (3rd ed). Washington DC: APA 1980.

14 Overall JE, Gorham DR. The Brief Psychiatric rating scale. Psychol Rep 1962;10:799-812.

15 Simpson GM, Angus JWS. A rating scale for extrapyramidal side effects. Acta Psychiatr Scand 1970;212(Suppl): 11-9.

16 Simpson GM, Lee JH, Zoubok B, Gardos G. A rating scale for tardive dyskinesia. Psychopharmacology 1979; 64:171-9.

17 Hindmarch I. Psychoactive drugs and driving. Psychiatry in Practice 1986;5:6-10.

18 Whiteman PD, Fowle ASE, Hamilton MJ, et al. The pharmacokinetics and pharmacodynamics of procyclidine in man. Beckenham; Wellcome Group Research and Development, 1982

19 Silverstone T. Drugs and driving. Br $\mathcal{f}$ Clin Pharmacol 1974;1:451-4.

20 Consensus Development Panel. Drug concentrations and driving impairment. $\mathcal{F} A M A 1985 ; 254: 2618-21$.

21 Department of Transport and The Central Office of Information. The Highway Code. London: HMSO 1978:14, 72 .

22 Nicholson AN. The significance of impaired performance. Int Clin Psychopharmacol 1988;3(Suppl 1):117-27.

23 Hindmarch I. The psychopharmacological Approach: Effects of psychotropic drugs on car handling. Int Clin Psychopharmacol 1988;3(Suppl 1):73-9.

\section{Sir Charles Bell 1774-1842}

In non-medical circles the best-known Bell is Joseph Bell (1837-1911) who was the source of inspiration and example for Conan Doyle's living legendSherlock Holmes. Bell's palsy is probably better known to doctors, but was not described by Joseph, but by the unrelated Sir Charles Bell, ${ }^{1}$ though Avicenna had much earlier described spastic, atonic and convulsive types of facial palsy. ${ }^{23}$

Born in Edinburgh, Charles Bell lectured in anatomy and surgery. In 1807 he distinguished between the sensory and motor nerves of the brain. In 1812 he was appointed to the Middlesex Hospital and studied gunshot wounds at Haslar Hospital after the battle of Corunna in 1809. After Waterloo he worked in Brussels. Studies of the spinal nerves led to furious arguments with Francois Magendie. Bell's experiments showed that: "stimulation of the anterior portion of the spinal marrow (spinal roots) convulsed animals more certainly than injury to the posterior portions". He recognised "four brains": two anterior (cerebral) and two posterior (cerebellar) ... . with full communications to ensure "their acting with perfect sympathy". $4 \mathrm{He}$ concluded: "the cerebrum and cerebellum were parts distinct in function and that every nerve possessing a double function obtained that by having a double root."

He worked on the brain which united the mind to the body: "Into it all the nerves from the external organs of the senses enter . . . nerves from the surface, nerves of touch, and nerves of peculiar sensibility; . . . and from it all the nerves which are agents of the will pass out" (via the anterior columns of the cord and its roots). "The cerebellum governs the operation of the viscera . . . their nerves go everywhere for the secret operations of the bodily frame ..."
The facial nerve he called "the respiratory nerve of the face". "In all the exhilarating emotions, the eyebrows, eyelids, the nostrils and the angles of the mouth are raised. In the depressing passions it is the reverse." 5

Bell entered another controversy when after experiments on the nerves in the ass, he erred in asserting that the fifth and seventh cranial nerves innervated the muscles of the face. Mayo (1796-1852) had earlier given the correct anatomy, but Bell later corrected his error: "the sensibility of the head and face depend upon the fifth pair of nerves . . the portio dura of the seventh nerve is the principal muscular nerve of the face". 6

Bell was a brilliant and versatile if controversial figure, well versed in comparative morphology, a prolific writer and a gifted water colour painter: the Royal College of Surgeons in Edinburgh contains many of his superb pictures of war injuries and anatomical exposures.

JMS PEARCE

1 Hale-White W. Sir Charles Bell. Great doctors of the nineteenth century. London: Edward Arnold, 1935 $42-62$.

2 Gruner OC. A treatise on the Canon of Medicine of Avicenna incorporating a translation of the first book. London, Luzac, 1930

3 Avicenna (Ibn Sina). Al Qanun fil-Tib. Arabic (Bullaq) ed, vol 2, Book 111. Cairo: Government Press, 1877:103-4. (Translated by Nathan B 1992).

4 Bell C. Idea of a new anatomy of the brain submitted for the observations of his friends. London. Straham and Preston 1811 (private circulation). Facsimile reprinted, Dawsons of Pall Mall, London 1966

5 Bell C. Essays on the anatomy and philosophy of expression, 2nd Essays on the anatomy and phil

6 Bell C. On the nerves of the face, being a second paper on the subject. Phil Trans Royal Soc 1829;119:317. 